\title{
Classification Method and Determination of Mountainous Area Types at Township Scales: A Case Study of Yuxi City, Yunnan Province
}

\author{
Li Wu, ${ }^{1,2}$ Binggeng Xie, ${ }^{2}$ Xiao Xiao, ${ }^{3}$ Bing Xue,,${ }^{1,3}$ and Jingzhong $L i \mathbb{D}^{4}$ \\ ${ }^{1}$ Department of Geography and Land Engineering, Yuxi Normal University, Yuxi, Yunnan 653100, China \\ ${ }^{2}$ College of Resources and Environmental Sciences, Hunan Normal University, Changsha, Hunan 410028, China \\ ${ }^{3}$ Institute of Applied Ecology, Chinese Academy of Sciences, Shenyang, Liaoning 110016, China \\ ${ }^{4}$ Xuchang University, Xuchang, Henan 46100, China \\ Correspondence should be addressed to Jingzhong Li; lijingzhong@xcu.edu.cn
}

Received 7 June 2020; Revised 7 August 2020; Accepted 23 August 2020; Published 3 September 2020

Academic Editor: Jianhong (Cecilia) Xia

Copyright $(92020 \mathrm{Li} \mathrm{Wu}$ et al. This is an open access article distributed under the Creative Commons Attribution License, which permits unrestricted use, distribution, and reproduction in any medium, provided the original work is properly cited.

\begin{abstract}
The high-resolution regional division of mountainous area types has important scientific significance for promoting precise management of land space and regional sustainable development. At present, the classification method of mountainous area types is mainly at the county level and above, while classifications for towns and villages are nearly nonexistent, which poses a technical challenge for rural revitalization and the construction of ecological civilization in mountainous areas. We used Yuxi city, Yunnan Province, as the target area of this research, which was based on GIS technology and Digital Elevation Model (DEM) data and socioeconomic environmental monitoring data. The most appropriate statistical unit (e.g., $2.8224 \mathrm{~km}^{2}$ ) for topographic relief was defined, and the study area was divided into six mountain types: flatlands, hills, low mountains, medium-low mountains, midmountains, and subhigh mountains. Based on the township scale, an index system and classification method dominated by the plain comprehensive index were established to carry out mountain area classifications at township scales. The 75 towns of Yuxi city can be classified into 27 plain towns, 23 mountain-plain towns, and 25 mountain towns from an empirical application perspective, which can provide strong data support and a reference basis for studying the evolution characteristics of land use in different geographical spaces and their interrelationships as well as differentiated land space planning and governance.
\end{abstract}

\section{Introduction}

As important regions that support water, energy, and biological diversity on earth [1], mountains occupy $24 \%$ of the global land surface area, provide homes for $12 \%$ of the world's population, indirectly offer goods and services for more than $40 \%$ of the global population, and play a very important role in the survival and development of humans [2,3]. In 1992, chapter 13 of Agenda 21, which was titled "Managing fragile ecosystems: sustainable mountain development," was released by the United Nations Conference on Environment and Development in Rio de Janeiro, while in November 1998, the United Nations General Assembly designated the year 2002 as the International Year of Mountains [3, 4]. From then on, mountains began to receive increasing attention, and development and construction in mountainous areas, as a common topic for mankind, has been highly valued by scholars at home and abroad [5-8]. As the natural foundation and core connotation of mountainous areas, mountains have some similarities and some differences with mountainous areas. Mountains are complex combinations of various geomorphological elements which focus on differences of landforms and geomorphology in nature $[9,10]$. However, mountainous areas emphasize regional combinations of humanity and geomorphology $[11,12]$ and interactions between humans and the geographical environment which is the research carrier for exploring the relationship between humans, land, and sustainable development [13]. However, with the rapid development of cities, which are the main study areas of human-earth relations $[14,15]$, mountainous areas have gradually become marginal areas and problem areas for 
economic development $[16,17]$ due to the fragility of mountain ecosystems and excessive human activity, soil erosion, deterioration of the ecological environment, economic backwardness, population poverty, and other problems [18-20]. The scientific definition of mountains and mountainous area types can provide a basis for classified development and classified policy, which are conducive to promoting the construction of ecological civilization and sustainable development in mountainous areas.

At present, many scholars have conducted research on the extraction of mountain information and classification methods of mountainous area types. The classification method of mountainous area types mainly uses the proportion of mountain area as the classification index, so the first task is to accurately define mountains types and their scopes [21]. Classification of mountain types is generally based on their geomorphologic elements such as topographic relief, elevation, and slope. In specific applications, some classifications use a single index to divide, while some classifications use a combination of multiple indicators to divide; compared with the use of a single index to divide mountain types, a comprehensive division based on multiple indicators can truly reflect mountain characteristics [22]. In the process of defining mountain types, remote sensing, geographic information technology, and DEM are mainly used to extract terrain factor information such as topographic relief and slope [23, 24]. Topographic relief, as the most important topographic factor for classifying mountain types $[11,25]$, is mainly influenced by determination of its optimal statistical unit $[26,27]$, which is generally determined by using mean-point analysis methods with the support of GIS software [28, 29]. However, results from the same region by using the same method are also different due to different levels of precision. For example, the optimal statistical unit of relief in Sichuan Province is calculated as $2.34 \mathrm{~km}^{2}$ [30] or $0.2025 \mathrm{~km}^{2}$ [31]; for the Hengduan Mountainous Region, this parameter is calculated as $14.98 \mathrm{~km}^{2}$ [32] or $2.62 \mathrm{~km}^{2}$ [33], and for the Tibetan Plateau, it is calculated as $1.17 \mathrm{~km}^{2}$ [34], $5.06 \mathrm{~km}^{2}$ [35], or $2.25 \mathrm{~km}^{2}$ [33]. It can be seen that the results of calculating the optimal statistical unit area of topographic relief in the same region are quite different; one of the reasons is the selection of the number of experimental units, which is further limited by the workload of manual extraction. Based on the Python programming language, the automatic extraction of experimental windows can be achieved, and the number of experimental units can be greatly increased, which is expected to improve the accuracy of the optimal statistical unit so that mountain types can be scientifically and reasonably defined based on the geomorphic characteristics of the study area.

Yuxi city in Yunnan Province, which has more mountains and less flatland, is located in the mountainous area of southwestern China, and these types of land resources are also a significant factor that affect the spatial differences in regional poverty [36]. As intermontane basins, river terraces, or relatively gentle piedmont valleys in the southwest mountainous area [37], plain areas have flat terrain and are conducive to construction and reclamation when compared with mountainous areas. Therefore, both productivity and land bearing capacity are relatively high in plain areas and are not only important agricultural production areas but are also gathering places for populations, economies, and cultures. However, in mountainous areas, natural conditions are harsh, loss of sand and soil is serious, and the level of social and economic development is low so the differences between these two geographical spaces are very clear. To achieve coordinated development of two different geographic spaces, scientific classification of mountainous areas is the prerequisite and foundation. The existing research on identification and classification of mountainous area types has created a relatively unified system at the macro scale, namely, the area proportions of mountain types are used [27, 38]. Scholars have divided mountainous and plain areas at the scale of provinces and counties, respectively, which has provided a certain theoretical basis for land use and protection of two different geographical spaces [39, 40]. However, with more detailed research, further refinement of spatial governance scales and further strengthening of the operability of local policies and with the implementation of the national "rural revitalization" policy, differentiated territorial space planning should proceed with more detail into the micro township scales. Hence, there is an urgent need to further subdivide mountainous area types at the microscale. In addition to dividing by the area proportions of mountain types as an important dividing index, superposition of human activities in land exploitation and utilization should also be considered to establish a comprehensive index system to conduct our high-precision classifications.

Therefore, on the basis of previous studies and by the combination of topographic and geomorphic data of Yuxi city, this study intends to increase the number of experimental units to 198 based on Python programming with the use of ArcGIS10.6 software to achieve automatic extraction of topographic relief. Then, the optimal statistical unit obtained is compared with relevant studies in an attempt to explore formation rules. At the same time, a comprehensive index system is constructed based on the proportion of mountain area, sum of flatland cultivated land and construction land area, and the comprehensive standardized value of flatland numbers and areas to divide the types of mountainous and plain areas at the scale of towns and villages. This classification in mountainous area types can provide data support for follow-up discussions on social and economic relationships between mountainous areas and plain areas and provide a scientific reference basis for the implementation of differentiated territorial space planning and precise governance.

\section{Materials and Methods}

2.1. Regional Overview. Yuxi city is located in the central region of Yunnan province. Its geographical coordinates are $23^{\circ} 19^{\prime} \sim 24^{\circ} 53^{\prime} \mathrm{N}$ and $101^{\circ} 16^{\prime} \sim 103^{\circ} 09^{\prime} \mathrm{E}$. It is adjacent to the provincial capital, Kunming, which is to the northeast; Chuxiong Autonomous Prefecture in the north; Pu'er city in the southwest and Honghe Autonomous Prefecture in the southeast, as is shown in Figure 1. The city has a maximum distance of $172 \mathrm{~km}$ from east to the west and maximum distance of $163.5 \mathrm{~km}$ from north to south with a total land 


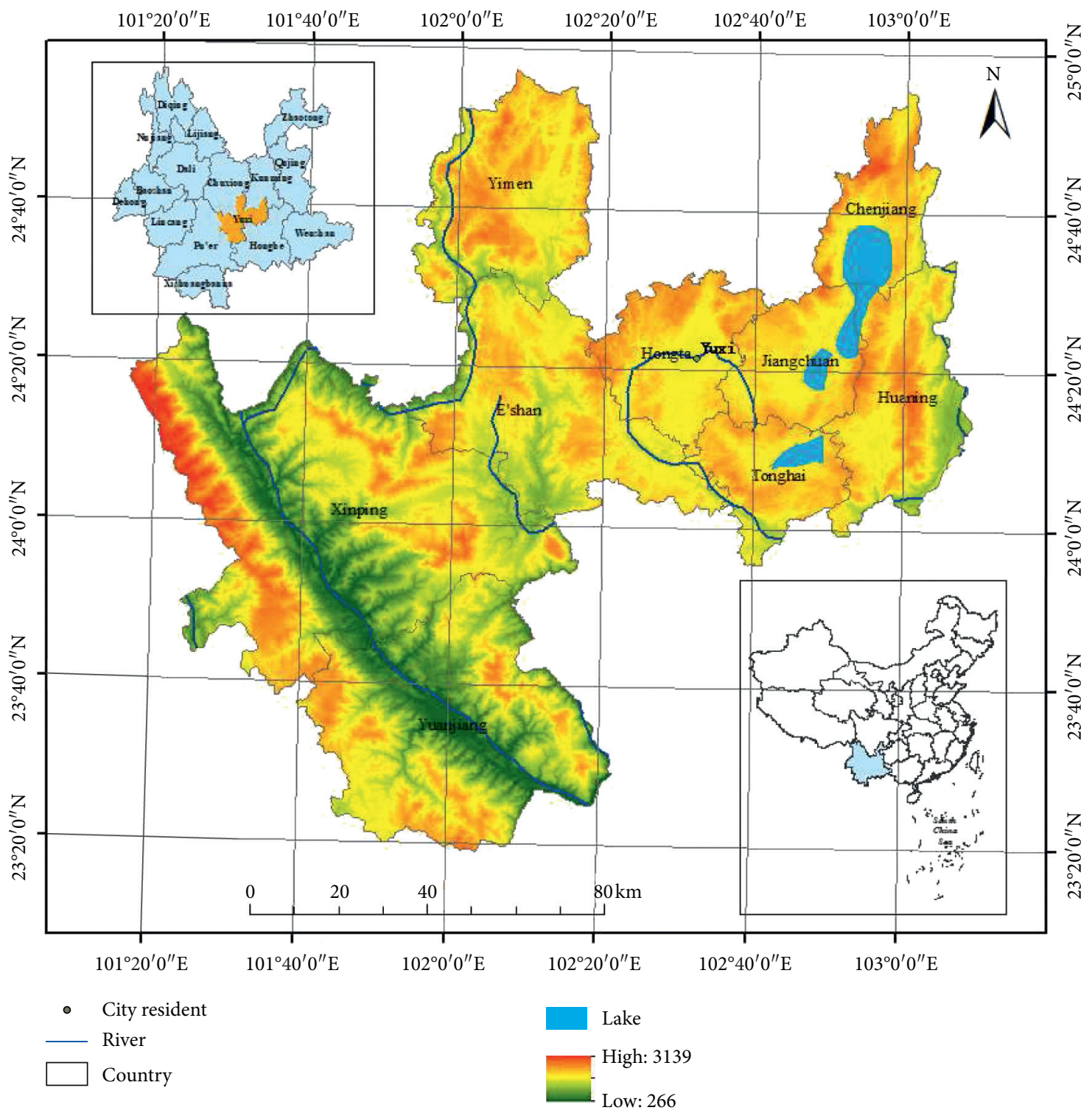

Figure 1: Location of study area.

area of $1.49 \times 104 \mathrm{~km}^{2}$. It has jurisdiction over 7 counties, 2 districts, and 75 townships.

Yuxi city is located on the Yunnan-Guizhou Plateau with high terrain in the Northwest and low terrain in the Southeast. The terrain is complex with staggered distributions of mountains, valleys, plateaus, and basins. Ailao Mountain to the West is a great barrier with mountains and valleys, and there are also some large fault collapse basins in the East and North. Due to the deep cutting of the Yuanjiang River Valley along the Yuanjiang fault zone on the east side of the Ailao Mountains, elevation differences greater than $2,000 \mathrm{~m}$ from the river to the top of the mountain and a mountain valley area were formed. Except for the Yuanjiang River, most of the research region is $1,500-1,800 \mathrm{~m}$ above sea level. The climate type is mainly a subtropical subhumid plateau monsoon climate without hot summers and cold winters with average annual temperatures of $17.4-23.8^{\circ} \mathrm{C}$ and average annual precipitation of $670-2,412 \mathrm{~mm}$. There are three plateau faulted lakes with abundant rainfall and high levels of farming which enjoy the reputation of "granary in central Yunnan" and "hometown of Yunnan tobacco" due to high grain yields and good quality of tobacco leaves.

2.2. Data Source and Processing. The DEM data used in the study are ASTER GDEMV2 $30 \mathrm{M}$, and these data were obtained from the Geospatial Data Cloud website (http:// www.gscloud.cn). ArcGIS 10.6 was applied to splice projections, and the administrative boundary of Yuxi city was then selected to obtain the DEM data for Yuxi city. The land vector data were obtained from the Resource and Environment Data Center of the Chinese Academy of Sciences (http://www.resdc.cn). Grid transformation was carried out with ArcGIS 10.6, and the land vector data of each town in Yuxi city were obtained by selecting the boundaries of towns and villages in Yuxi city. 


\subsection{Methods}

2.3.1. Mountain Type Definition Method. Considering the mountain classification index system proposed by the United Nations Environment Programme and relevant scholars [12, 22, 41], high-altitude areas are generally directly classified as mountains, while middle- and low-altitude areas should be defined as mountain types in combination with slopes, local elevation changes, and relief. According to the DEM used in the experiment, Yuxi city is located in the southwest mountainous area, and its elevation range is between 266 and $3,139 \mathrm{~m}$. Statistically, areas up to $1,500-2,000 \mathrm{~m}$ sea level account for $49.15 \%$ of the city and form nearly half of the entire research area. Through slope analysis, it was found that the average slope is $21^{\circ}$ and that mountains are widely distributed. The highest relief degree of the land surface (RDLS) is $1,335 \mathrm{~m}$, with little overall undulation, but local undulation is great. Therefore, in the classification of mountainous area types at the township scale, RDLS should be considered as an important index and be combined with altitude and slope to classify mountain types. When the altitude is below $1,500 \mathrm{~m}$, mountain types should be divided according to the degree of relief. The influence of slope factor should also be considered when the altitude is between $1,500 \mathrm{~m}$ and $3,500 \mathrm{~m}$. Therefore, the mountains in Yuxi city are divided into hills, low mountains, medium-low mountains, midmountains, and subhigh mountains (Table 1).

2.3.2. Topographic Relief Calculation. At present, most scholars extract topographic relief by adopting window analysis methods based on the spatial analysis module in ArcGIS10.6. The level of topographic relief in a window can be obtained by calculating the difference between the maximum and minimum values of focus statistics for different window pixels $n \times n(n=2,3, \ldots, 198,199)$. Based on a window movement step distance of 1 , automatic extraction of terrain relief for different windows can be achieved by programming Python modules.

For calculations of topographic relief, selection of the optimal size of statistical unit (the optimal moving window) is the key. In this study, mean variable point analysis was used to determine the optimal statistical unit. The basic principle of this method is based on the existence of only one inflection point which changes from steep to gradual. The mathematical expression is that there are data sequences $\left\{x_{i}\right\}$, and among them, $i=1,2,3, \ldots, N(1,2, \ldots, 198)$, where $N$ is the number of samples and the sample is divided into two segments bounded by the point $x_{i}$ and then the arithmetic mean value of each section $\bar{x}_{i 1}, \bar{x}_{i 2}$ and sample mean $\bar{x}$ are calculated separately:

$$
\begin{aligned}
S_{i} & =\sum_{t_{1}=1}^{i-1}\left(x_{t 1}-\bar{x}_{i 1}\right)^{2}+\sum_{t_{2}=i}^{N}\left(x_{t 2}-\bar{x}_{i 2}\right)^{2}, \\
S & =\sum_{i=1}^{N}\left(x_{i}-\bar{x}\right)^{2}
\end{aligned}
$$

TABLE 1: Indicators of mountain type definition.

\begin{tabular}{lccc}
\hline Elevation & RDLS & Slope & Mountain types \\
\hline $0-500$ & $>100 \mathrm{~m}$ & - & Hill \\
$500-1000$ & $\begin{array}{c}>300 \mathrm{~m} \text { within the scope } \\
\text { of } 2.82 \mathrm{~km}^{2}\end{array}$ & & Low mountain \\
& $\begin{array}{c}\text { Medium-low } \\
\text { m within the scope } \\
1000-1500\end{array}$ & & mountain \\
$1500-2500$ & of $2.82 \mathrm{~km}^{2}$ & $>8^{\circ}$ & Midmountain \\
$2500-3500$ & & $>5^{\circ}$ & Subhigh mountain \\
\hline
\end{tabular}

where $S_{i}$ and $S$ are intermediate calculated values $t_{1}=1,2$, $\ldots, i-1$ and $t_{2}=i, i+1, \ldots, N$. Then, the expected value $E\left(S-S_{i}\right)$ can be calculated and the window size corresponding to the maximum expected value is the optimal statistical unit area.

2.3.3. Classification Methods for Mountainous and Plain Areas. Since there is no reference in existing studies to the classification method of mountainous area and plain area types based on the township scale, this study refers to the method of mountain area proportion based on the county scale, but there are improvements to two indicators of flatland-farmland area proportions, and number of flatlands $\left(\right.$ area $\left.\geq 100 \mathrm{~km}^{2}\right)$ [39]. With the rapid development of the social economy and constant increases of urbanization levels, large amounts of flatland cultivated land have been occupied by construction [42, 43]. Therefore, there is a certain deficiency when using only the proportion of flatland cultivated land for evaluations. In this study, the superposition of flatland construction land area proportions and flatland cultivated land area proportions is taken as an index, namely, the proportion of flatland cultivated land and construction land. At the same time, it is difficult for the area of a single flatland to reach $100 \mathrm{~km}^{2}$ at the township scale, so flatlands that are greater than or equal to $1 \mathrm{~km}^{2}$ will be chosen as the standard according to the definition of $\mathrm{Ag}$ ricultural Geography of Yunnan [44], field research, and data analysis. Meanwhile, it is unfair to evaluate only using the number of flatlands as the size of the flatland area has more practical significance for the division. Therefore, the standardized value of flatland ( $a r e a \geq 1 \mathrm{~km}^{2}$ ) in every village or town will be obtained by combining the number of flatlands and the area of flatlands. The formulas are as follows:

$$
\begin{aligned}
\mathrm{PCI} & =\frac{\mathrm{Q}_{\mathrm{FB}}}{\mathrm{Q}_{\mathrm{FB}_{m}}} \times w_{1}+\frac{\mathrm{Q}_{\mathrm{LA}}}{\mathrm{Q}_{\mathrm{LA}_{m}}} \times w_{2}+\mathrm{PA}_{n} \times w_{3}, \\
\mathrm{Q}_{\mathrm{FB}} & =\frac{\mathrm{FA}_{p}+\mathrm{BA}_{p}}{\mathrm{TFA}+\mathrm{TBA}} \times 100 \%, \\
\mathrm{Q}_{\mathrm{LA}} & =\frac{\mathrm{LA}_{p}}{\mathrm{TLA}} \times 100 \%, \\
\mathrm{PA}_{n} & =\sum_{i=1}^{m} N_{i},
\end{aligned}
$$

where PCI is the plain composite index, $\mathrm{FA}_{p}$ is the flatland farmland area, $\mathrm{BA}_{p}$ is the flatland construction land area, 
TFA is the total farmland area, TBA is the total construction land area, $Q_{F B}$ is the proportion of flatland farmland and construction land, $\mathrm{LA}_{p}$ is the flatland land area, TLA is the total land area, $Q_{\mathrm{LA}}$ is the proportion of flatland area, $Q_{\mathrm{FB}_{m}}$ is the maximum proportion of flatland farmland and construction land, $Q_{\mathrm{LA}_{m}}$ is the maximum proportion of flatland land area, $\mathrm{PA}_{n}$ is the standardized value of flatland (area $\geq 1 \mathrm{~km}^{2}$ ) in every villages or towns, $N_{i}$ is the standardized value of every flatland (area $\left.\geq 1 \mathrm{~km}^{2}\right)$, and $m$ is the number of flatlands (area $\left.\geq 1 \mathrm{~km}^{2}\right) ; w_{1}, w_{2}$, and $w_{3}$, are the weights of $\mathrm{Q}_{\mathrm{FB}}, \mathrm{Q}_{\mathrm{LA}}$, and $\mathrm{PA}_{n}$, respectively; and $w_{1}+w_{2}+$ $w_{3}=100$ to ensure that the result of PCI is between 0 and 100 , with values of 50,35 , and 15 , respectively.

Combined with the leading index and auxiliary index, the specific dividing standard for plain areas and mountainous areas is shown in Table 2.

\section{Results}

3.1. Optimum Statistical Unit. By use of Python module programming and $2 \times 2,3 \times 3, \ldots, 198 \times 198$, to $199 \times 199$ windows, the topographic relief was automatically extracted, and different window sizes and their corresponding average topographic relief values were obtained, as shown in Table 3.

Origin 2019 software was used to perform logarithmic equation fitting for the corresponding statistical areas and average topographic relief for each window shown in Table 3. The fitting curve of relief degree in Yuxi city was obtained. The equation used is $y=216.2167+159.9691 \times \ln (x+0.4009)$, and the decision coefficient is $R^{2}=0.9967$ (Figure 2). The fitting effect was good and passed the statistical test. Figure 2 shows that the average topographic relief in the research area increased with increases in window area. Below a window area of $2 \mathrm{~km}^{2}$, the average topographic relief increased greatly and the curve was steeper. However, between 2 and $4 \mathrm{~km}^{2}$, the curve changed from steep to gradual, and above $4 \mathrm{~km}^{2}$, the increase of the average topographic relief decreased and the curve became flatter. According to formulas (1) and (2), the $S_{i}, S$ and $S-S_{i}$ values and differential fitting curves of $S_{i}$ and $S$ can be calculated (Table 4, Figure 3). Table 4 and Figure 3 show that the difference between $S_{i}$ and $S$ reached a maximum value at the 55th point, i.e., the turning point where the curve changed from steep to gradual. Thus, a $56 \times 56$ window $\left(2.8224 \mathrm{~km}^{2}\right)$ is the optimal statistical unit area for the topographic relief of Yuxi city.

\subsection{Definition of Mountain Types. Based on ASTER GDEM} data, the elevations (Figure 4(a)) and slopes (Figure 4(b)) were extracted, and the topographic relief was extracted by using a $56 \times 56$ window (Figure $4(\mathrm{c})$ ). The classification of mountain types in Yuxi city in ArcGIS10.6 was accomplished by using the previously mentioned mountain type definition indicators, and the results are shown in Figure 4(d). According to Figure 4(d), Yuxi city is mainly dominated by mountains, and the flatland is very small. In the defining results of various mountain types, the hilly area is $13,294.32 \mathrm{hm}^{2}$, the low mountain area is $121,727.41 \mathrm{hm}^{2}$, the medium-low mountain area is $250,393.05 \mathrm{hm}^{2}$, the midmountain area is $820,116.80 \mathrm{hm}^{2}$, and the subhigh mountain area is $20,460.24 \mathrm{hm}^{2}$. The highest percentage of each mountain type in the total land area is midmountains (54.96\%), which is followed by medium-low mountains (16.78\%), low mountains (8.16\%), subhigh mountains $(1.37 \%)$, and hills $(0.89 \%)$. Flatlands are mainly distributed in some large fault collapse basins in the east, namely, the Hongta District, Tonghai County, Jiangchuan County, and Chengjiang County. The elevations are between 1,500 and $2,500 \mathrm{~m}$, but the slopes are relatively low (below $8^{\circ}$ ) and the topographic relief is less than $300 \mathrm{~m}$ (Figures 4(a)-4(c)). Hills are mainly distributed in the part of Yuanjiang County that is located to the west of Yuxi city, in a valley with lower elevations. Xinping County also has a small amount of hills distribution, which is staggered with some flatlands. Because the elevations are between 500 and 1,000 m, the low mountains are mainly distributed around the southwest river valley in Xinping and Yuanjiang but tend to spread to the periphery of E'shan and Yimen. In addition to Xinping, Yuanjiang, and E'shan, medium-low mountains are widely distributed and extend from the west to the east along the southern periphery of each county, but there are no distributions in the north. With elevations of 1,500-2,500 $\mathrm{m}$ and as the largest distribution type, midmountains are distributed in all counties and districts, especially in the east and central regions. Subhigh mountain areas are less common and are mainly distributed in the Ailao Mountain area of Xinping but other counties such as Yimen, Chengjiang, and Huaning also have sporadic distributions.

\subsection{Classification of Mountainous Areas and Plain Areas.} With the help of formulas (3)-(6), the proportion of total flatland cultivated land and construction land area, proportion of flatland land area, and number and area of flatlands (area $\geq 1 \mathrm{~km}^{2}$ ) for each town in Yuxi city were calculated, and the plain comprehensive index was also calculated (Table 5, Figures 5(a)-5(c)). According to the standard for dividing plain areas and mountainous areas in Yuxi city, the plain comprehensive index was used as the leading index and the other three indexes were used as auxiliary indexes; the 75 villages and towns were divided into plain areas, mountain-plain areas, and mountainous areas. First, by using the leading indicators, 14 plain regions, 34 mountain-plain regions, and 27 mountainous regions were defined. Plain regional villages and towns include Yudai, Xingmeng, Xiushan, Yousuo, Sijie, Qianwei, Jiangcheng, Longjie, Liqi, Dajie, Yuxing, Luju, Panxi, and Chunhe. Second, when combined with the field topographic conditions and by means of the auxiliary index "proportion of flatland farmland and construction land" and "proportion of flatland land area," there were 13 villages and towns with a plain comprehensive index greater than 40 , the proportions of flatland cultivated land and construction land were all greater than $50 \%$, and the proportions of flatlands were all greater than $20 \%$ among the 32 divided mountain-plain villages and towns. Therefore, these 13 villages and towns were further divided into plain regions, which include 
TABLE 2: Division criteria of plain areas and mountainous areas.

\begin{tabular}{lcccc}
\hline \multicolumn{2}{c}{ Classification indicator } & & \multicolumn{2}{c}{ Classification criteria } \\
& Plain towns & Mountain-plain towns & Mountain towns \\
\hline \multirow{2}{*}{ Leading index } & $\mathrm{PCI}$ & $\geq 50$ & $20-50$ & $<20$ \\
& $\mathrm{Q}_{\mathrm{FB}}(\%)$ & $\geq 50$ & $30-50$ & $<30$ \\
\multirow{2}{*}{ Auxiliary index } & $\mathrm{Q}_{\mathrm{LA}}(\%)$ & $\geq 20$ & $10-20$ & $<10$ \\
& $\mathrm{PA}_{n}$ & $\geq 0.2$ & $\geq 0.1$ & 0 \\
\hline
\end{tabular}

TABle 3: The relation between the size of the window and the average topographic relief.

\begin{tabular}{lcc}
\hline Window size & Area $\left(\mathrm{km}^{2}\right)$ & Average relief $(\mathrm{m})$ \\
\hline $2 \times 2$ & 0.0036 & 13.3291 \\
$3 \times 3$ & 0.0081 & 26.3569 \\
$4 \times 4$ & 0.0144 & 39.0506 \\
$5 \times 5$ & 0.0225 & 51.3448 \\
$6 \times 6$ & 0.0324 & 63.2301 \\
$7 \times 7$ & 0.0441 & 74.6776 \\
$8 \times 8$ & 0.0576 & 85.7005 \\
$9 \times 9$ & 0.0729 & 96.3601 \\
$10 \times 10$ & 0.0900 & 106.5712 \\
$11 \times 11$ & 0.1089 & 116.5744 \\
$\ldots$ & $\ldots$ & $\ldots$ \\
$53 \times 53$ & 2.5281 & 387.8541 \\
$54 \times 54$ & 2.6244 & 391.2082 \\
$55 \times 55$ & 2.7225 & 396.9445 \\
$56 \times 56$ & 2.8224 & 400.1518 \\
$57 \times 57$ & 2.9241 & 406.2713 \\
$\ldots$ & $\ldots$ & $\ldots$ \\
$150 \times 150$ & 20.25 & 699.0040 \\
$151 \times 151$ & 20.5209 & 699.7820 \\
$152 \times 152$ & 20.7936 & 706.0452 \\
$\ldots$ & $\ldots$ & $\ldots$ \\
$194 \times 194$ & 33.8724 & 789.0474 \\
$195 \times 195$ & 34.2225 & 789.3074 \\
$196 \times 196$ & 34.5744 & 802.8152 \\
$197 \times 197$ & 34.9281 & 802.5625 \\
$198 \times 198$ & 35.2836 & 801.0867 \\
$199 \times 199$ & 35.6409 & 805.1577 \\
\hline & &
\end{tabular}

Beicheng, Fenghuang, Jiujie, Xiongguan, Huanian, Guishan, and Longquan. Finally, among the 27 mountain regional villages or towns that were divided, Qinglong and Pingdian, whose plain comprehensive index was greater than 15 and the standardized value of flatland $\left(\right.$ area $\geq 1 \mathrm{~km}^{2}$ ) was greater than 0.2 , were adjusted as mountain-plain regions. Therefore, 27 plain towns, 23 mountain-plain towns and 25 mountainous towns were classified in Yuxi city (Table 6 and Figure 5(d)).

The spatial distributions of mountainous area types in Yuxi city are shown in Figure 5(d). Plain towns are mainly distributed in the eastern area, i.e., the alluvial plain areas around three lakes (e.g., Fuxian Lake, Xingyun Lake, and Qilu Lake). Only two of 27 plain towns are located in E'shan and Xinping in the central and western parts of Yuxi city while one is in the northern part of Yimen, nine are in Hongta, six are in Tonghai, five are in Jiangchuan, three are in Chengjiang, and one is in Huaning. The mountain-plain towns are mainly distributed on the periphery of plain regions and are located between plain and mountainous regions; the terrain consists of mountains and flatlands alternating with each other. Mountainous towns are mainly concentrated in Xinping in the western Yuxi area, Yimen in the northern area, and E'shan in the central area while Huaning County also has two mountainous regions. The main terrain is mountains with sporadic flatlands.

\section{Conclusion and Discussion}

(1) Through Python module programming using different windows for automatic extraction of topographic relief and the use of Origin 2019 software for logarithmic equation fitting, it was found that the average topographic relief and window area in Yuxi city had the highest fitting degree under the logarithmic equation $y=a-b \times \ln (x+c)$ and that the determination coefficient was 0.9967 . However, the logarithmic fitting equation used by other scholars in the research process was $y=a \times \ln (x)+b$, and the determination coefficients were close to 0.95 [45], 0.96 [34], 0.97, or 0.98 [30, 33]. Therefore, the log 3P1 logarithmic equation was adopted to conduct higher degrees of fitting between the window area and average topographic relief. At the same time, the optimal statistical unit in this study is $56 \times 56$, or $2.8224 \mathrm{~km}^{2}$, which is similar to the optimal statistical units of $2.43 \mathrm{~km}^{2}$ and $2.62 \mathrm{~km}^{2}$ in southwest China that were calculated by Zhong and $\mathrm{Lu}$ [33] and further verified the accuracy of the optimal statistical unit used in this study. However, Zhang and Zhao [32] calculated the area of the optimal statistical unit of topographic relief in the Hengduan Mountain area as $14.98 \mathrm{~km}^{2}$ by using the mean point variation method, which was quite different from the result of this study. First, the DEM data resolution adopted by Zhang et al. was $90 \mathrm{~m}$ but was $30 \mathrm{~m}$ in this study, which showed great differences in accuracy. Second, the number of experimental units studied by Zhang et al. was only 34 which was quite different from the 198 mobile units used in this study. In addition, Zhang et al. [46] calculated the optimal statistical unit area for Qihe River Basin topographic fluctuations as $0.1296 \mathrm{~km}^{2}$, and Yu et al. [25] calculated the optimal statistical unit area for the Three Gorges Area as $0.15 \mathrm{~km}^{2}$ by using the mean variation analysis method. Based on the above research results, it was determined that the more complex the terrain, the larger is the area of the optimal statistical unit; the 


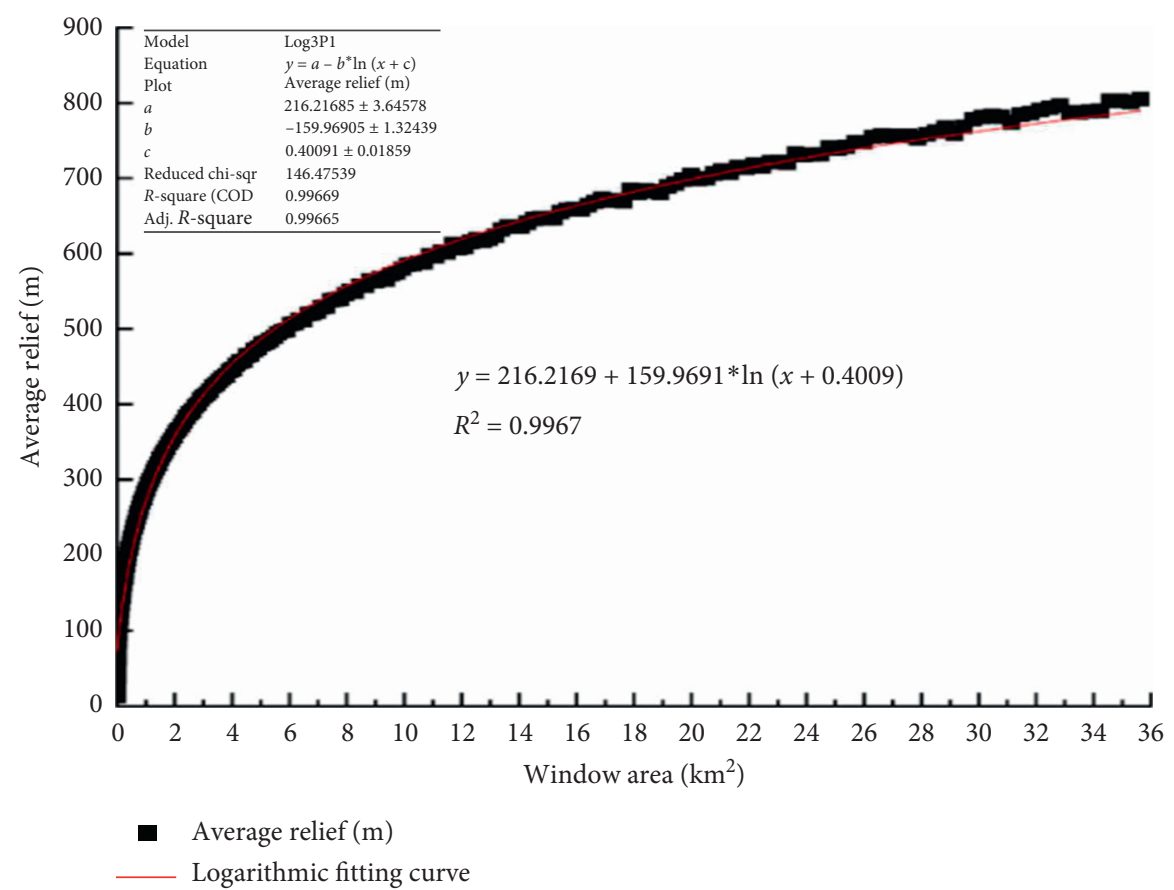

Figure 2: Fitting curve between statistic window and average relief.

TABle 4: Statistical results of mean change points.

\begin{tabular}{lcc}
\hline$i$ & $S_{i}$ & $S-S_{i}$ \\
\hline 2 & 256.8821 & 14.14172 \\
3 & 243.5664 & 27.45738 \\
4 & 231.4536 & 39.57018 \\
5 & 220.4428 & 50.58099 \\
6 & 210.3915 & 60.63237 \\
7 & 201.1761 & 69.84774 \\
8 & 192.6937 & 78.33014 \\
9 & 184.8562 & 86.16761 \\
10 & 177.5978 & 93.42601 \\
11 & 170.8505 & 100.1733 \\
$\ldots$ & $\ldots$ & $\ldots$ \\
54 & 79.7803 & 191.2435 \\
55 & 79.74534 & 191.2785 \\
56 & 79.77197 & 191.2519 \\
57 & 79.82627 & 191.1976 \\
58 & 79.93202 & 191.0918 \\
$\ldots$ & $\ldots$ & $\ldots$ \\
189 & 252.8267 & 18.19711 \\
190 & 254.6119 & 16.41197 \\
191 & 256.3961 & 14.62772 \\
192 & 258.2216 & 12.80223 \\
193 & 260.0561 & 10.96778 \\
194 & 261.8934 & 9.130391 \\
195 & 263.7389 & 7.284901 \\
196 & 265.5471 & 5.47671 \\
197 & 267.3651 & 3.658694 \\
198 & 269.197 & 1.826839 \\
\hline & &
\end{tabular}

flatter the surface, the smaller the area of the optimal statistical unit. Additionally, the larger the research scope, the smaller the area of the optimal statistical unit.

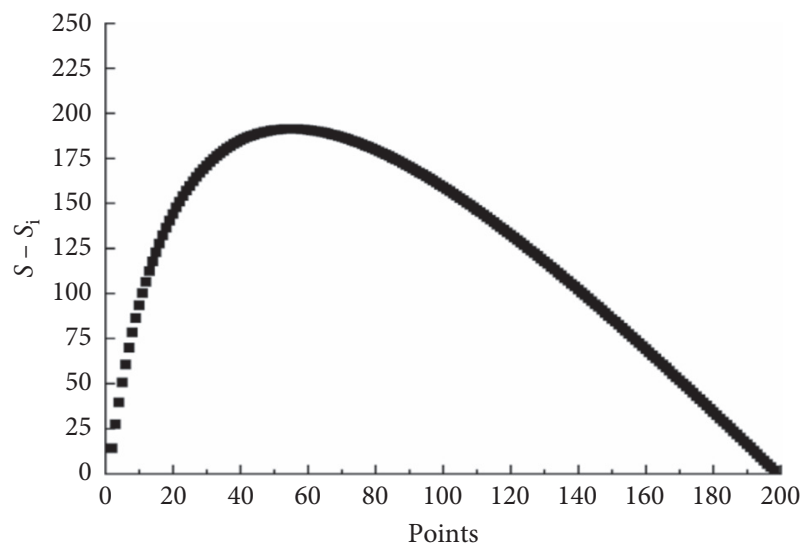

Figure 3: Difference fitting curve of $S$ and $S_{i}$.

(2) In the process of defining mountain types, it was found that it is most scientific to divide by using elevation, topographic relief, and slope through several experiments. Yuxi city is located in Mountains of Southwest China, with an average elevation of approximately $1,800 \mathrm{~m}$. If the mountain type is defined only by using altitude, there are only mountains in our study area. However, during the field investigations, in addition to the low elevation valley areas along the Yuanjiang River, it was found that, in the alluvial plains in the eastern region, especially around the three large lakes, midelevation plain was present, which has elevations from 1,500 to $2,500 \mathrm{~m}$ and topographic relief of less than $100 \mathrm{~m}$. In most studies, a slope of $5^{\circ}$ is considered to be the critical slope for middle elevation plateaus and middle elevation 

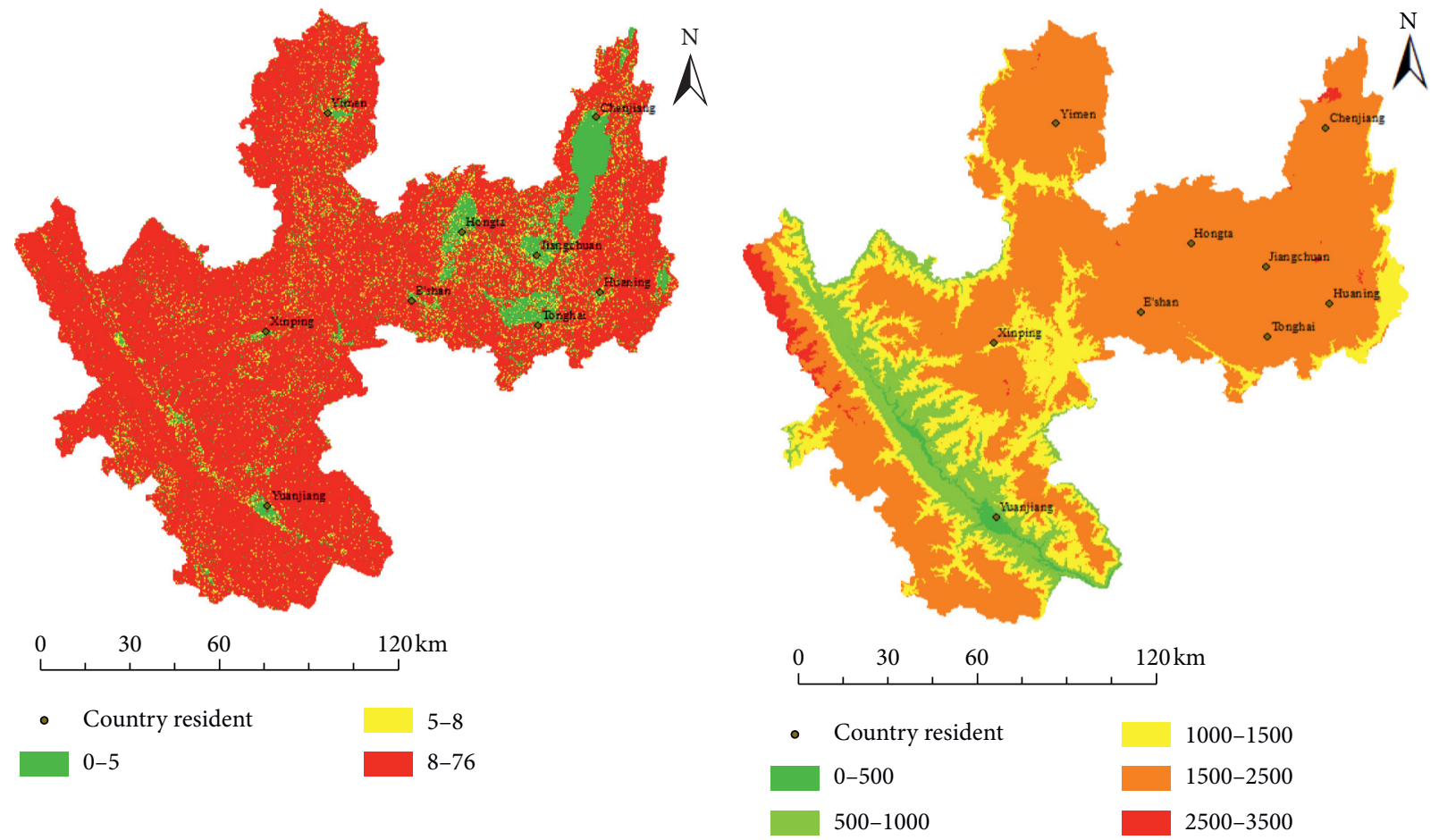

(a)

(b)
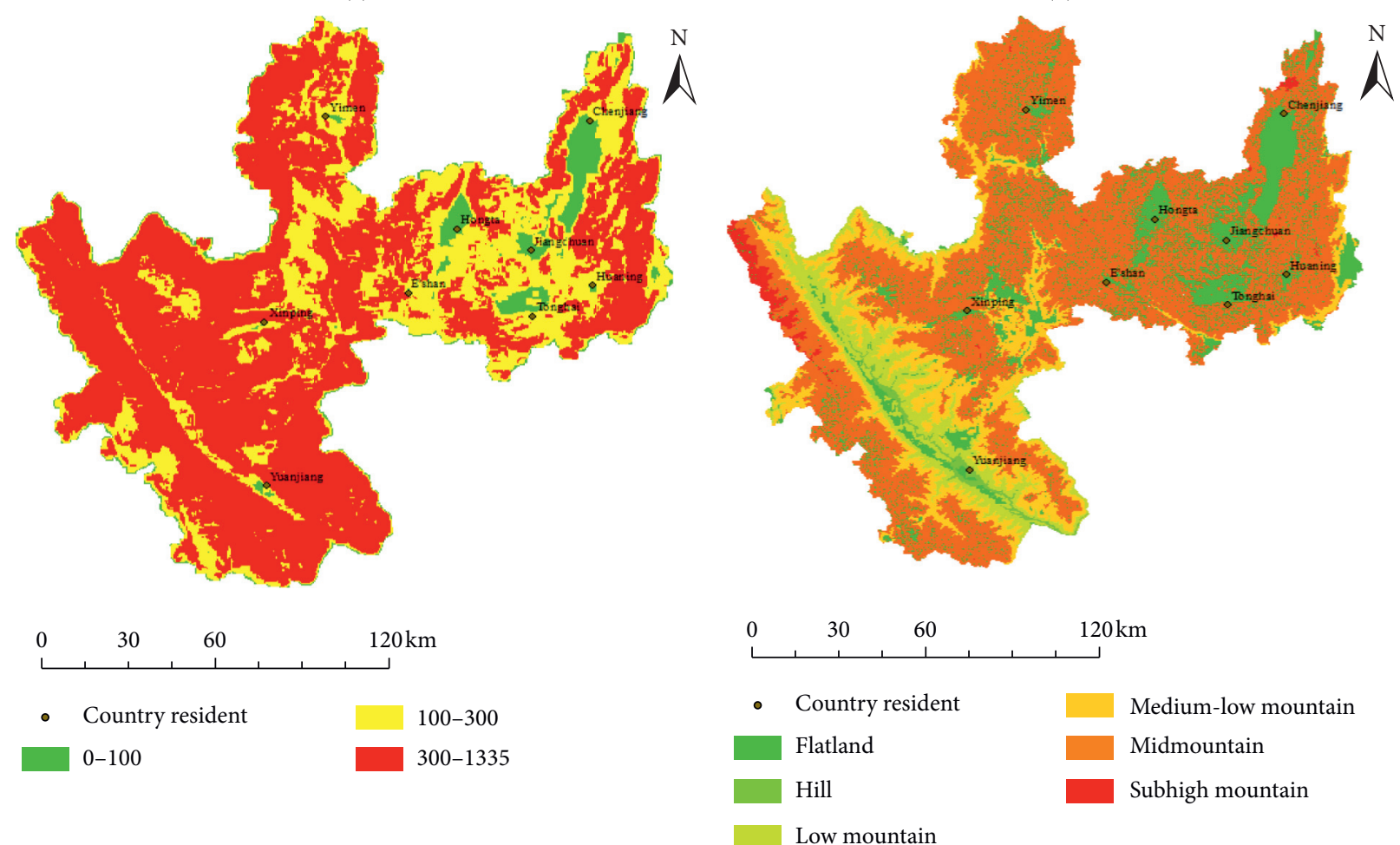

(c)

(d)

Figure 4: Terrains and mountain types in Yuxi city. (a) Slope $\left({ }^{\circ}\right)$. (b) Altitude (m). (c) Topographic relief (m). (d) Mountain types.

mountains, but this value is not applicable to the definition of the critical mountain slope in Yuxi city. By comparing the results of multiple experiments with field and remote sensing images and by combining the definition of flatland slope by $<$ Yunnan agricultural geography $>$ and other scholars, it is most reasonable to define the mountain critical slope as $8^{\circ}$, which not only can meet the definition of the mountain type but can also conform to the difference between plain areas and mountainous areas in the field. 
TABLE 5: Mountainous areas and plain areas classification index of each villages or towns.

\begin{tabular}{|c|c|c|c|c|}
\hline Villages or towns & $\begin{array}{l}\text { Proportion of flatland farmland and } \\
\text { construction land }\end{array}$ & $\begin{array}{l}\text { Proportion of flatland } \\
\text { area }\end{array}$ & $\begin{array}{l}\text { Standardized value of } \\
\text { flatlands }\end{array}$ & $\begin{array}{c}\text { Plain comprehensive } \\
\text { index }\end{array}$ \\
\hline Anhua & 0.3965 & 0.2711 & 0.0105 & 30.22 \\
\hline Beicheng & 0.6704 & 0.3326 & 0.2226 & 49.47 \\
\hline Chahe & 0.1212 & 0.1115 & 0.0560 & 11.10 \\
\hline Chunhe & 0.7067 & 0.3031 & 0.2461 & 50.55 \\
\hline Dajie & 0.7735 & 0.4963 & 0.2297 & 60.88 \\
\hline Dalongtan & 0.1526 & 0.1460 & 0.0140 & 13.34 \\
\hline Dayingjie & 0.6783 & 0.2778 & 0.1754 & 47.12 \\
\hline Dianzhong & 0.3146 & 0.1839 & 0.0000 & 22.69 \\
\hline Dong'e & 0.3529 & 0.2545 & 0.5983 & 36.23 \\
\hline Fenghuang & 0.6218 & 0.3954 & 0.0007 & 46.05 \\
\hline Fenglu & 0.6218 & 0.4703 & 0.0011 & 48.85 \\
\hline Fuliangpeng & 0.3409 & 0.1396 & 0.0133 & 22.56 \\
\hline Gaocang & 0.6229 & 0.3851 & 0.0321 & 46.19 \\
\hline Gaoda & 0.4678 & 0.2745 & 0.1572 & 36.14 \\
\hline Guishan & 0.6160 & 0.2355 & 0.1348 & 41.80 \\
\hline Haikou & 0.2458 & 0.3368 & 0.2656 & 28.92 \\
\hline Hexi & 0.4634 & 0.2624 & 0.1575 & 35.47 \\
\hline Huaxi & 0.1809 & 0.1403 & 0.0874 & 15.65 \\
\hline Huanian & 0.5387 & 0.2334 & 0.5245 & 43.68 \\
\hline Gasa & 0.2484 & 0.0623 & 0.1116 & 16.49 \\
\hline Jianxing & 0.1762 & 0.1763 & 0.0000 & 15.44 \\
\hline Jiangcheng & 0.5945 & 0.5162 & 0.9606 & 63.58 \\
\hline Jiucun & 0.2526 & 0.2246 & 0.0000 & 21.09 \\
\hline Jiujie & 0.5924 & 0.3367 & 0.1757 & 45.00 \\
\hline Jiuxi & 0.4857 & 0.3220 & 0.0000 & 36.45 \\
\hline Laochang & 0.1783 & 0.0688 & 0.0584 & 12.41 \\
\hline Liqi & 0.8798 & 0.4180 & 0.1237 & 61.72 \\
\hline Lishan & 0.3412 & 0.2271 & 0.0000 & 25.64 \\
\hline Lijiang & 0.2786 & 0.0974 & 0.2188 & 20.93 \\
\hline Liujie & 0.3833 & 0.1523 & 0.0302 & 25.42 \\
\hline Longjie & 0.5431 & 0.4683 & 1.1580 & 62.17 \\
\hline Longquan & 0.5576 & 0.2570 & 0.1626 & 40.08 \\
\hline Longtan & 0.0472 & 0.0154 & 0.0000 & 2.95 \\
\hline Luju & 0.6652 & 0.4734 & 0.3439 & 56.29 \\
\hline Luohe & 0.2134 & 0.1183 & 0.0000 & 15.15 \\
\hline Lvzhi & 0.0517 & 0.0352 & 0.0000 & 3.91 \\
\hline Mili & 0.0356 & 0.0629 & 0.0000 & 4.14 \\
\hline Mosha & 0.2343 & 0.0994 & 0.3239 & 20.35 \\
\hline Nanuo & 0.0487 & 0.0313 & 0.0000 & 3.62 \\
\hline Nagu & 0.6363 & 0.4543 & 0.0015 & 48.99 \\
\hline Ningzhou & 0.3033 & 0.2052 & 0.0581 & 23.79 \\
\hline Panxi & 0.5024 & 0.4765 & 0.6575 & 52.92 \\
\hline Pingdian & 0.1626 & 0.1445 & 0.2868 & 17.88 \\
\hline Pingzhang & 0.0277 & 0.0639 & 0.0661 & 4.77 \\
\hline Pubei & 0.2595 & 0.1881 & 0.0880 & 21.40 \\
\hline Qianwei & 0.7539 & 0.5706 & 0.2937 & 63.63 \\
\hline Qinglongchang & 0.1139 & 0.0450 & 0.0075 & 7.52 \\
\hline Qinglong & 0.1768 & 0.1780 & 0.2656 & 19.53 \\
\hline Shijie & 0.1383 & 0.1344 & 0.1051 & 13.55 \\
\hline Shuangjiang & 0.3701 & 0.1465 & 0.0465 & 24.78 \\
\hline Shuitang & 0.0162 & 0.0202 & 0.0000 & 1.57 \\
\hline Sijie & 0.7682 & 0.5751 & 0.3267 & 65.01 \\
\hline Tadian & 0.3864 & 0.2370 & 0.2003 & 31.29 \\
\hline Tonghongdian & 0.0574 & 0.0625 & 0.0000 & 5.22 \\
\hline Tongchang & 0.1306 & 0.0942 & 0.0000 & 10.09 \\
\hline Wazhi & 0.0268 & 0.0391 & 0.0000 & 2.81 \\
\hline Xiaojie (1) & 0.1124 & 0.0788 & 0.0000 & 8.60 \\
\hline Xiaojie (2) & 0.4076 & 0.2160 & 0.0506 & 29.32 \\
\hline Xiaoshiqiao & 0.3424 & 0.1890 & 0.0000 & 24.28 \\
\hline
\end{tabular}


Table 5: Continued.

\begin{tabular}{lcccc}
\hline Villages or towns & $\begin{array}{c}\text { Proportion of flatland farmland and } \\
\text { construction land }\end{array}$ & $\begin{array}{c}\text { Proportion of flatland } \\
\text { area }\end{array}$ & $\begin{array}{c}\text { Standardized value of } \\
\text { flatlands }\end{array}$ & $\begin{array}{c}\text { Plain comprehensive } \\
\text { index }\end{array}$ \\
\hline Xinhua & 0.1828 & 0.0920 & 0.0918 & 14.01 \\
Xingmeng & 0.9940 & 0.8225 & 0.0881 & 82.03 \\
Xiongguan & 0.6111 & 0.3586 & 0.0386 & 44.70 \\
Xiushan & 0.8404 & 0.6523 & 0.2641 & 70.59 \\
Yanhe & 0.5993 & 0.3606 & 0.1724 & 46.20 \\
Yangwu & 0.2965 & 0.1368 & 0.3709 & 25.59 \\
Yangchajie & 0.0413 & 0.0922 & 0.0000 & 5.52 \\
Yangjie & 0.0745 & 0.0642 & 0.0000 & 6.15 \\
Yangzong & 0.4395 & 0.2925 & 0.1229 & 34.87 \\
Yangguang & 0.5435 & 0.4016 & 0.2521 & 46.11 \\
Yaojie & 0.0672 & 0.0330 & 0.0048 & 4.68 \\
Yingyuan & 0.1783 & 0.1236 & 0.0493 & 14.33 \\
Yousuo & 0.6108 & 0.6369 & 0.8493 & 67.24 \\
Yudai & 0.9375 & 0.9375 & 0.0757 & 83.29 \\
Yuxing & 0.7044 & 0.6403 & 0.0153 & 5.57 \\
Zhelong & 0.0698 & 0.0251 & 0.0000 & 4.44 \\
\hline
\end{tabular}

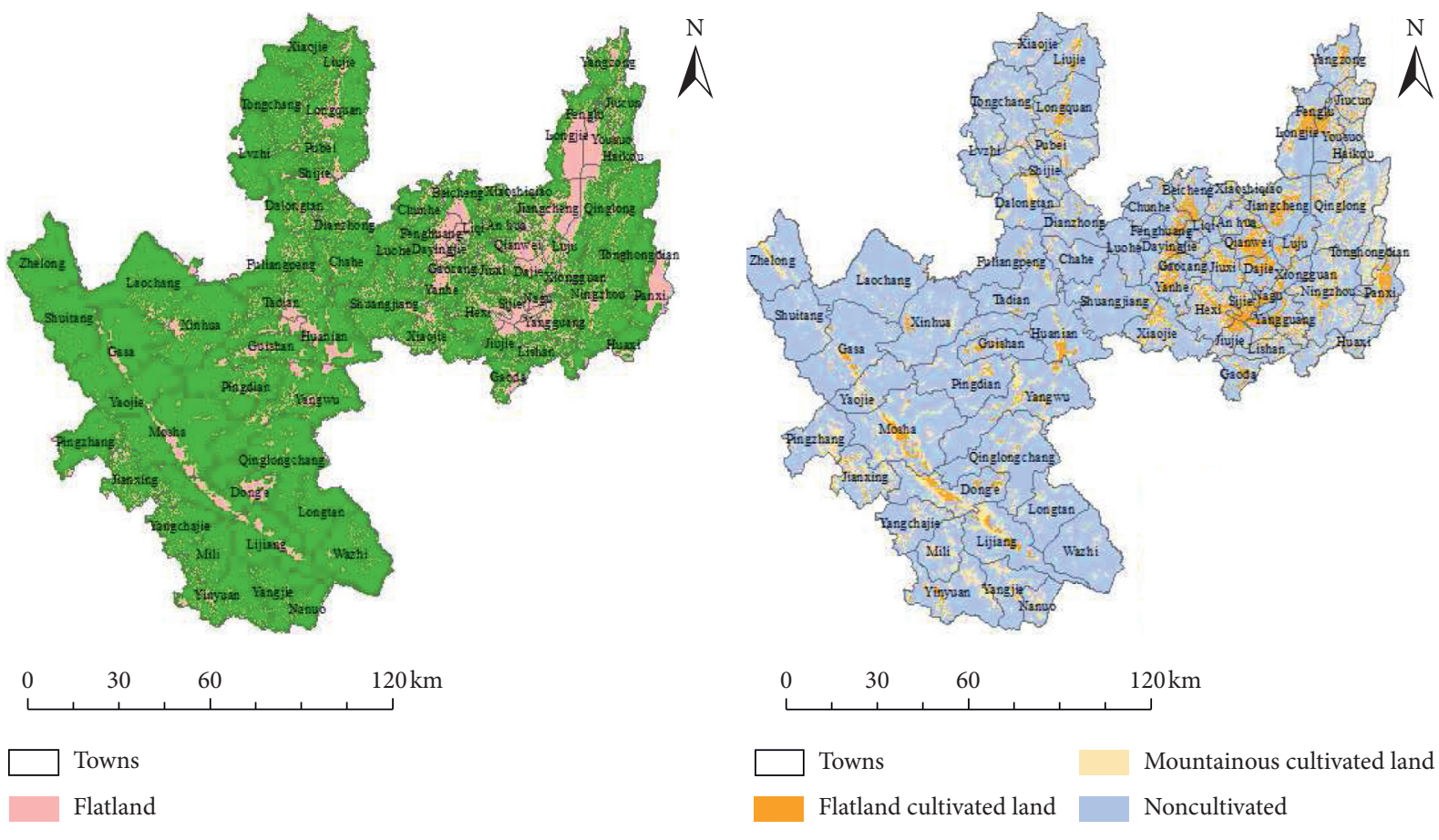

(a)

(b)

Figure 5: Continued. 


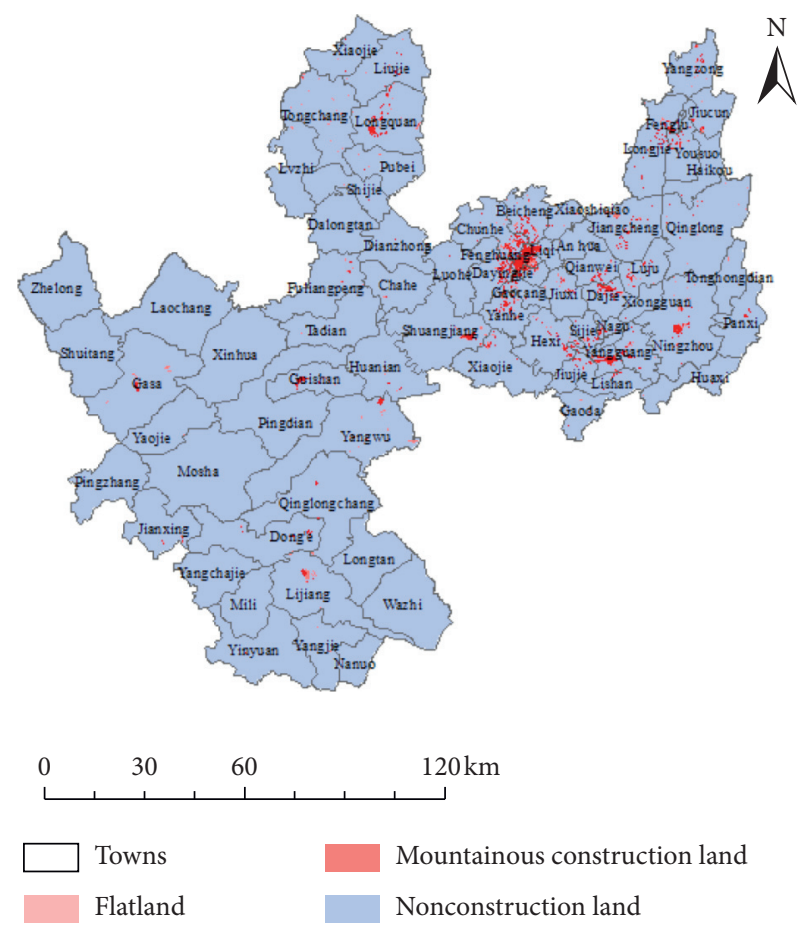

(c)

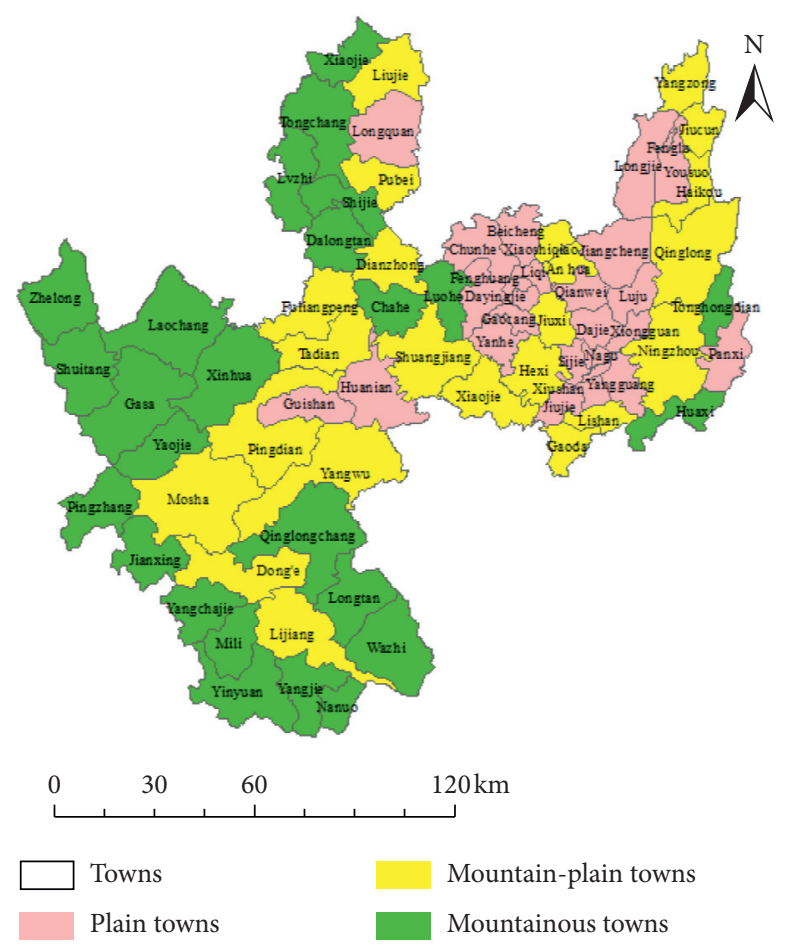

(d)

Figure 5: (a) Land types, (b) cultivated land types, (c) construction land types, and (d) town types in Yuxi city.

TABLE 6: Classification scheme of plain areas and mountainous areas.

\begin{tabular}{lcc}
\hline Classification & $\begin{array}{c}\text { Number of } \\
\text { towns }\end{array}$ & Name of towns \\
Plain towns & 27 & $\begin{array}{c}\text { Yudai, Xingmeng, Xiushan, Yousuo, Sijie, Qianwei, Jiangcheng, Longjie, Liqi, Dajie, Yuxing, Luju, } \\
\text { Panxi, Chunhe, Beicheng, Nagu, Fenglu, Dayingjie, Yanhe, Gaocang, Yangguang, Fenghuang, Jiujie, } \\
\text { Xiongguan, Huanian, Guishan, Longquan }\end{array}$ \\
\hline $\begin{array}{l}\text { Mountain-plain } \\
\text { towns }\end{array}$ & 23 & $\begin{array}{c}\text { Gaoda, Dong'e, Jiuxi, Tadian, Yangzong, Hexi, Haikou, Anhua, Yangwu, Xiaojie (2), Lishan, } \\
\text { Xiaoshiqiao, Liujie, Dianzhong, Ningzhou, Fuliangpeng, Qinglong, Jiucun, Mosha, Pubei, } \\
\text { Shuangjiang, Lijiang, Pingdian }\end{array}$ \\
\hline Mountain towns & 25 & $\begin{array}{c}\text { Jianxing, Luohe, Huaxi, Yinyuan, Dalongtan, Gasa, Xinhua, Shijie, Laochang, Chahe, Tongchang, } \\
\text { Xiaojie (1), Qinglongchang, Yangie, Yangchajie, Tonghongdian, Yaojie, Mili, Zhelong, Pingzhang, } \\
\text { Lvzhi, Nanuo, Wazhi, Longtan, Shuitang }\end{array}$ \\
\hline
\end{tabular}

(3) According to the classification method of Yang and Zhao [39], the classification index for mountainous areas and plain areas was adopted but two improvements were made. First, with increased urbanization levels, flatland farmland with low topographic relief and low slopes is constantly swallowed up by construction land. If only the proportion of flatland cultivated land is used as the measurement index, the results will be biased. The proportion of flatland cultivated land will be reduced to or even less than $50 \%$ due to occupation by construction land, which is inconsistent with reality. Second, the number of flatlands as a measurement index is not sufficiently accurate. When dividing plain areas and mountainous areas, it is more important to combine the area and number of flatlands, especially the area. If only the number of flatlands is used as the measurement, there will be large areas of flatlands with small numbers in some villages and towns but the comprehensive value is very low. For example, one flatland in Longjie has an area of $74.26 \mathrm{~km}^{2}$, while six flatlands in Gasa have a total area of only $14.18 \mathrm{~km}^{2}$. According to Yang's calculation method, the index value of Longjie is only 2.5 while that of Gasa is 15 , which is far from the situation. Therefore, it is more reasonable to standardize the flatland area $\left(\geq 1 \mathrm{~km}^{2}\right)$ and evaluate it in combination with the number of flatlands owned by each township. After this improvement, most of the results are consistent with the field research, but some villages and towns still show exceptions. For example, the proportion of flatland cultivated land in 
Dong'e town is greater than $35 \%$, the proportion of flatland land is greater than $25 \%$, and there are 6 flatlands whose areas are each greater than $1 \mathrm{~km}^{2}$. Meanwhile, the total area of flatlands is $49.83 \mathrm{~km}^{2}$, but the plain comprehensive index is only 36.21 , which can only be classified into a mountain-plain town. Therefore, the accuracy of the dividing index between mountainous areas and plain areas needs to be further improved and discussed.

\section{Data Availability}

The dataset used to support the findings of this study is available from the corresponding author upon request.

\section{Conflicts of Interest}

The authors declare that there are no conflicts of interest regarding the publication of this paper.

\section{Acknowledgments}

This research was financially supported by the National Natural Science Foundation of China under Grant nos. 41971116 and 41807081, the Natural Scientific Research Fund Project of Yunan Province under Grant no. 2017FH001-045, and the National Key Research and Development Project under Grant no. 2016YFC0502406.

\section{References}

[1] M. F. Price, "Forests in sustainable mountain development," in IUFRO Division 8 Conference on Environmental Forest Science, vol. 54, pp. 39-49, Kyoto University, Kyoto, Japan, 1998.

[2] L. Jansky, "UNU and sustainable mountain development," Mountain Research and Development, vol. 20, no. 2, pp. 188-189, 2000.

[3] A. Schild, "The case of the Hindu Kush-Himalayas ICIMOD's position on climate change and mountain systems," Mountain Research and Development, vol. 28, no. 3/4, pp. 328-331, 2008.

[4] L. Jansky, J. D. Ives, K. Furuyashiki, and T. Watanabe, "Global mountain research for sustainable development," Global Environmental Change, vol. 12, no. 3, pp. 231-239, 2002.

[5] T. Breu, D. Maselli, and H. Hurni, "Knowledge for sustainable development in the Tajik Pamir mountains," Mountain Research and Development, vol. 25, no. 2, pp. 139-146, 2005.

[6] T. Scheurer and S. Jost, "Sustainable mountain development beyond Rio +20: regional and national perspectives," Mountain Research and Development, vol. 32, no. 1, pp. 92-95, 2012.

[7] W. Jin, Y. F. Cui, S. N. Wu, and D. Q. Cheng, "Ecological risk resonance of urbanization and its effect on geohazard disaster: the case of Freetown, Sierra Leone," Urban Ecosystems Early Access, pp. 1-12, 2020.

[8] C. S. Zhan, R. X. Zhao, and S. Hu, "Emergy-based sustainability assessment of forest ecosystem with the aid of mountain eco-hydrological model in Huanjiang County, China," Journal of Cleaner Production, vol. 251, p. 14, Article ID 119638, 2020.

[9] M. Meybeck, P. Green, and C. Vörösmarty, “A New typology for mountains and other relief classes: an application to global continental water resources and population distribution," Mountain Research and Development, vol. 21, no. 1, pp. 34-45, 2001.

[10] Y. Li, X. Yang, H. Cai, L. Xiao, X. Xu, and L. Liu, "Topographical characteristics of agricultural potential productivity during cropland transformation in China," Sustainability, vol. 7, no. 1, pp. 96-110, 2014.

[11] G. A. Tang, J. Strobl, J. Y. Gong, M. D. Zhao, and Z. J. Chen, "Evaluation on the accuracy of digital elevation models," Journal of Geographical Sciences, vol. 11, no. 2, pp. 209-216, 2001.

[12] R. Hassan, R. Scholes, and N. Ash, Ecosystems and Human Well-Being: Current State and Trends: Findings of the Condition and Trends Working Group, Island Press, Washington, DC, USA, 2005.

[13] B. Xue, J. Z. Li, X. Xiao et al., "Overview of man-land relationship research based on POI data: theory, method and application," Geography and Geo-Information Science, vol. 35, no. 6, pp. 51-60, 2019, in Chinese.

[14] B. Xue, X. Xiao, J. Z. Li, and X. Xie, "Analysis of spatial economic structure of Northeast China cities based on points of interest big data," Scientia Geographica Sinica, vol. 40, no. 5, pp. 691-700, 2020, in Chinese.

[15] J. Yang, W. L. Liu, Y. H. Li, Q. S. Ge, and M. Santos, "Simulating intraurban land use dynamics under multiple scenarios based on fuzzy cellular automata: a case study of Jinzhou District, Dalian," Complexity, vol. 2018, Article ID 7202985, 17 pages, 2018.

[16] A. Schild and E. Sharma, "Sustainable mountain development revisited," Mountain Research and Development, vol. 31, no. 3, pp. 237-241, 2011.

[17] Y. Yang, Y. Y. Zhao, G. D. Ding, and G. L. Gao, "Effects of urbanization on landscape patterns in a mountainous area: a case study in the Mentougou District, Beijing, China," Sustainability, vol. 8, no. 11, p. 14, 2016.

[18] T. Kohler and S. W. von Dach, "CDE links regional research and global efforts for sustainable mountain development," Mountain Research and Development, vol. 35, no. 2, pp. 203-207, 2015.

[19] M. Kulikov, U. Schickhoff, A. Gröngröft, and P. Borchardt, "Modelling soil erodibility in mountain rangelands of southern Kyrgyzstan," Pedosphere, vol. 30, no. 4, pp. 443-456, 2020.

[20] Y. X. Zhang, P. Halder, X. N. Zhang, and M. Qu, “Analyzing the deviation between farmers' land transfer intention and behavior in China's impoverished mountainous area: a Logistic-ISM model approach," Land Use Policy, vol. 94, Article ID 104534, 2020.

[21] X. Huang, X. Huang, M. Liu, B. Wang, and Y. Zhao, "Spatialtemporal dynamics and driving forces of land development intensity in the Western China from 2000 to 2015," Chinese Geographical Science, vol. 30, no. 1, pp. 16-29, 2020.

[22] X. H. Zhong and S. Z. Liu, "Research on the mountain classification in China," Mountain Research, vol. 32, no. 2, pp. 129-140, 2014.

[23] D. Karátson, T. Telbisz, and B. S. Singer, "Late-stage volcano geomorphic evolution of the Pleistocene San Francisco Mountain, Arizona (USA), based on high-resolution DEM analysis and 40Ar/39Ar chronology," Bulletin of Volcanology, vol. 72, no. 7, pp. 833-846, 2010.

[24] W. Cheng, N. Wang, M. Zhao, and S. Zhao, "Relative tectonics and debris flow hazards in the Beijing mountain area from DEM-derived geomorphic indices and drainage analysis," Geomorphology, vol. 257, pp. 134-142, 2016. 
[25] H. Yu, Y. Luo, S. Liu, Y. Wang, Y. Yang, and W. D. Liu, "The influences of topographic relief on spatial distribution of mountain settlements in Three Gorges Area," Environmental Earth Sciences, vol. 74, no. 5, pp. 4335-4344, 2015.

[26] C. Liu, W. Sun, and H. Wu, "Determination of complexity factor and its relationship with accuracy of representation for DEM terrain," Geo-spatial Information Science, vol. 13, no. 4, pp. 249-256, 2010.

[27] O. D. A. Prima, A. Echigo, R. Yokoyama, and T. Yoshida, "Supervised landform classification of Northeast Honshu from DEM-derived thematic maps," Geomorphology, vol. 78, no. 3-4, pp. 373-386, 2006.

[28] L. Wang and X. J. Tong, "Analysis on relief amplitude based on change point method," Geography and Geo-Information Science, vol. 23, no. 6, pp. 65-67, 2007, in Chinese.

[29] S. B. Liu, Y. P. Cui, F. X. Lu, and X. Y. Qin, "The analysis of relief amplitude in Qinghai Province based on GIS," in Proceedings of the International Conference on Geoinformatics, IEEE, Kaifeng, China, June 2013.

[30] J. J. Zhang, Y. H. Li, and L. Q. Zhu, "Relief amplitude based on county units in West Henan mountain area and its correlation with distribution of population and economic activities," Areal Research and Development, vol. 38, no. 2, pp. 55-60, 2019, in Chinese.

[31] J. C. Zhang and W. Z. Zhou, "Spatial autocorrelation between topographic relief and population/economy in Sichuan Province," Bulletin of Soil and Water Conservation, vol. 39, no. 1, pp. 250-257, 2019, in Chinese.

[32] Y. Zhang and Y. L. Zhao, "Mountainous area divisions at county level in Hengduan Mountains based on DEM," Journal of Guizhou Normal University (Natural Sciences), vol. 34, no. 6, pp. 8-14, 2016, in Chinese.

[33] J. Zhong and T. Lu, "Optimal statistical unit for relief amplitude in Southwestern China," Bulletin of Soil and Water Conservation, vol. 38, no. 1, pp. 175-181, 2018, in Chinese.

[34] H. H. Han, T. Gao, H. Yi et al., "Extraction of relief amplitude based on change point method: a case study on the Tibetan Plateau," Scientia Geographica Sinica, vol. 32, no. 1, pp. 101104, 2012, in Chinese.

[35] X. R. Zhang and K. Dong, "Neighborhood analysis-based calculation and analysis of multi-scales relief amplitude," Advanced Materials Research, vol. 468-471, pp. 2086-2089, 2012.

[36] Z. Ma, X. Chen, and H. Chen, "Multi-scale spatial patterns and influencing factors of rural poverty: a case study in the Liupan Mountain Region, Gansu Province, China," Chinese Geographical Science, vol. 28, no. 2, pp. 296-312, 2018.

[37] Y. B. Li, H. Chen, and G. J. Luo, "Spatial distribution of different scale flatland in Guizhou Province, China," Scientia Geographica Sinica, vol. 39, no. 11, pp. 1830-1840, 2014, in Chinese.

[38] Y.-p. Fang and B. Ying, "Spatial distribution of mountainous regions and classifications of economic development in China," Journal of Mountain Science, vol. 13, no. 6, pp. 1120-1138, 2016.

[39] Z. S. Yang and Q. G. Zhao, "Study on dividing flatland county, semi-mountainous \& semiflatland county and mountainous county in Yunnan Province based on the second national land survey," Journal of Natural Resources, vol. 29, no. 4, pp. 564-574, 2014, in Chinese.

[40] Y. L. Zhao and X. B. Li, "Spatial correlation between type of mountain area and land use degree in Guizhou Province, China," Sustainability, vol. 8, no. 9, p. 849, 2016.
[41] M. Schuler, E. Stucki, and O. Roque, Mountain Areas in Europe: Analysis of Mountain Areas in EU Member States, Acceding and Other European Countries, European Commission, Brussels, Belgium, 2004.

[42] B. Xue, L. M. Zhang, Y. Geng, B. Mitchell, and W. X. Ren, "Extended land-use coding system and its application in urban brownfield redevelopment: case study of Tiexi District in Shenyang, China," Journal of Urban Planning and Development, vol. 142, no. 3, in Chinese, Article ID 05015014, 2016.

[43] A. D. Guo, Y. Q. Zhang, Q. Hao, and J. H. C. Xia, "Monitoring and simulation of dynamic spatiotemporal land use/cover changes," Complexity, vol. 2020, Article ID 3547323, 12 pages, 2020.

[44] Editing Group of Yunnan Agricultural Geography, Yunnan Agricultural Geography, Yunnan People's Publishing House, Kunming, China, 1981, in Chinese.

[45] R. H. Wang, J. C. Yang, S. W. Zhang, L. P. Chang, L. M. Pu, and $\mathrm{K} . \mathrm{Bu}$, "Analysis on the relief amplitude in Northeast China based on ASTER GDEM and mean change point method," Journal of Arid Land Resources and Environment, vol. 30, no. 6, pp. 49-54, 2016, in Chinese.

[46] J. Zhang, W. Zhu, F. Zhao et al., "Spatial variations of terrain and their impacts on landscape patterns in the transition zone from mountains to plains-a case study of Qihe River Basin in the Taihang Mountains," Science China Earth Sciences, vol. 61, no. 4 , pp. $450-461,2018$. 